\title{
Complex approach to selection and evaluation of the fire safety measures to be applied during repair of refrigerated holds
}

\author{
Zygmunt Sychta, Prof. \\ Szczecin University of Technology
}

\author{
ABSTRACT
}

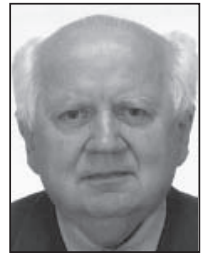

This paper presents an analysis_of fire hazard during repair work of refrigerated hold with a view of specificity of its equipment and construction, as well as the algorithm of the system of analysis and evaluation of safety measures and their effectiveness. The assessment of effectiveness was based on the applied fire safety measures. Selected actions and technical measures for fire safety must make it possible to prevent fire ignition in hardly accessible spaces behind the boarding of hold walls and in air cooling chambers as unnoticed fire may very fast propagate to the next holds and ship compartments due to flue drafts.

Keywords: refrigerated hold, ship repair work, fire safety

\section{CONSTRUCTION AND EQUIPMENT OF REFRIGERATED HOLDS}

Refrigerated vessels constitute a special group of ships. Palettization of cargo has caused major changes in construction of refrigerated vessel holds. A modern refrigerated vessel has the refrigerated holds with vertical walls parallel to ship centreline. Thermal insulation made of mineral or glass wool is placed directly on metal surfaces of hold walls. A waterresistant lacquered plywood or aluminium sheet serves as a timbering of insulation.

Old versions of refrigerated ships or other ships adapted to transport palettized refrigerated cargo have been fitted with

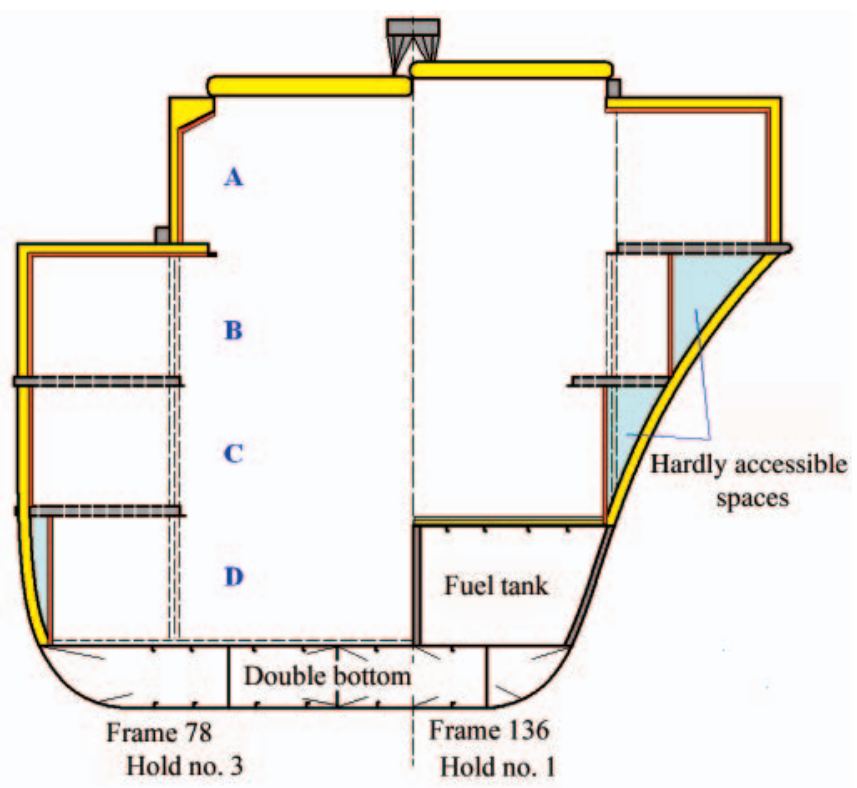

Fig. 1. An example of old version of thermal insulation of refrigerated holds the different thermal insulation system of refrigerated holds as shown in Fig. 1.

A hard polyurethane foam and mineral wool are the thermal insulation placed directly on steel surface of ship's side structure. The refrigerated hold walls are made of waterresistant lacquered plywood fixed to vertical steel construction. A perforated steel tweendeck construction forms the ceiling of hardly accessible spaces. As a result of that construction hardly accessible spaces made of flammable materials have been created along refrigerated holds. Cross-section area of hardly accessible side spaces varies from 0 to about $2 \mathrm{~m}^{2}$ depending on hull curvature of refrigerated vessel. Such spaces located between the holds are separated by steel bulkheads.

A ventilation system ensures an appropriate temperature required for shipped cargo. Forced air circulation in refrigerated holds is initiated by axial fans combined with coolers. They force the air to flow under gratings across the whole width of the hold (Fig. 2). The intake air flows into cargo space through grating holes. Then the air flows back to cold room through ducts placed under hold ceiling.

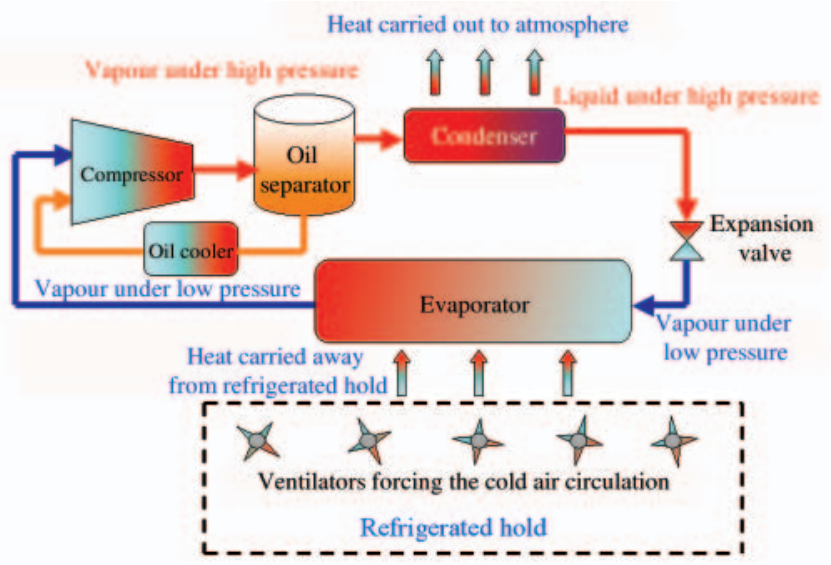

Fig. 2. Schematic diagram of air cooling system 
Another function of the refrigerated hold ventilation system is to freshen up the air in refrigerated holds (by applying two air changes per hour $[\mathrm{ACH}]$ ) that has to limit concentration of the gases released from cargo as to not exceed its maximum permissible level (e.g. for bananas, citrus fruits). The ventilation system also controls air humidity in the hold.

Every refrigerated hold usually consists of four air-cooling units: two of them placed on the hold bottom and the other two - above the tweendeck. Air coolers with direct evaporation of refrigerant are used most often. The coolers together with fans are located in separate rooms whose walls are made of waterresistant lacquered plywood.

A number of air changes (rate) in refrigerated hold depends on type of cargo and it varies between $30 \div 120$ [ACH]. Air circulation rate is adjusted to requirements of shipped cargo by switching on an appropriate number of fans installed in the unit or by switching-on a suitable gear if two-gear fan is used.

The air circulation is used if to dry thermal insulation of the hold in hardly accessible spaces in refrigerated holds is necessary in order to protect the insulation from loss of its insulating features, that may be caused by moisture. A very dry air flowing slowly through ducts of hold insulation, absorbs the moisture which penetrates from hold by diffusion, and then releases it by condensation in the cooler.

Piston, screw and rotary compressors require to be lubricated by liquid oil which decreases friction, carries away heat, seals piston in cylinder and stuffing-box, dampens vibrations and reduces noise. To decrease amount of oil in installation, highefficiency oil separators located close to the compressor, are applied (Fig. 3). The separated oil re-circulates immediately to crankcase of compressor, that is performed either continuously or periodically depending on type of compressor.

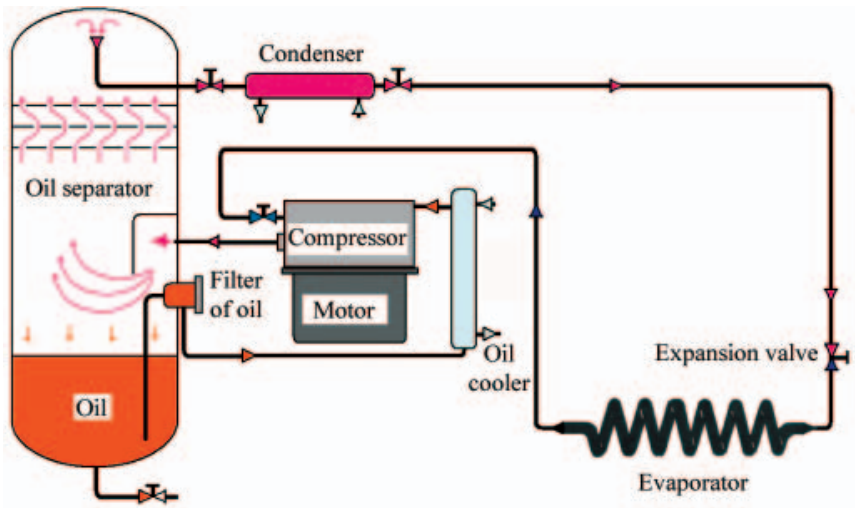

Fig. 3. Schematic diagram of cooling system

3 to $10 \%$ amount of the oil which seeps into the cooling system, brings in additional problems of design and operational character. During operation of cooling device, apart from refrigerant circulation, the oil must flow without obstacles. The following measures must be undertaken to achieve it:

is all horizontal sections of conduits must be sloped in direction of refrigerant flow

is diameters of conduits must be appropriately selected so that refrigerant velocity in vertical sections would cause oil convection

is design of the installation must prevent oil gravitational drift to compressor during its standstill

is oil filling-up must be possible also during motion

is design of the installation must prevent oil accumulation during motion and standstill.

Every technical system has an acceptable emergency range of operational parameters within which it is capable of working.
Then it should be possible to perform effective corrections and repairs, and setting of automatic safety systems etc. Loss of control of progress of a hazardous situation occurs when the control and safety systems and repair personnel are not capable of correcting a dangerous trend in values of the parameters that indicate the area of safe operation of an installation or device, that may lead to damage, escalation of accident and release of hazardous substances or amount of energy. Fire, an uncontrolled combustion of materials in time and space, is a frequent effect of loss of control of progress of an emergency situation.

\section{THE COMPLEX APPROACH TO ANALYSIS AND EVALUATION OF EFFECTIVENESS OF APPLIED SAFETY MEASURES}

The above presented description of construction and equipment of refrigerated holds reveals major problems of fire safety during operation and repair work. The fire accidents are mainly triggered by frequently underestimated factors which cause dynamic progress of fire. Knowledge of the factors may reduce consequences and financial losses caused by fire accidents.

The process of identification of a level of knowledge of technical requirements, environmental protection and external factors is used to determine purposeful and planned actions which have to contribute in maintaining the high level of fire safety (Fig. 4). The process is controlled by current assessing the results of implementation of the established schedule. The process is characterized by multi-stage character, continuity and dynamics, logic and time sequence, complex approach to tasks and a wide range of performance options.

The basic features of the system are as follows:

$\rightarrow$ it is a social and technical creative action including scientific and technical elements

$\rightarrow$ it is a purposeful human organization created by people of various attitudes, motives and education

$\overrightarrow{2}$ it is an open system which means that it has no strict limits and does not care only of itself

$\Rightarrow$ it deals with information of essential importance

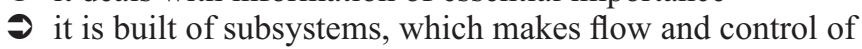
information possible

$\rightarrow$ feedbacks applied in it make its control and optimisation possible

D it is so designed as to achieve targets by using various methods.

Man is an important element of fire safety system. During ship repair, ship's crew is incomplete and a number of people not permanently connected with the ship, e.g. shipyard workers, co-operators, supervisors and others, increases. For this reason the incomplete crew is not capable of controlling the situation on the ship. After working hours many crew members leave their ship and only watch remains on duty. Worth adding that fire accidents occur mostly in the night.

The above presented four-stage system may be iterated repeatedly. A number of iterations depends on frequency and range of changes made in a given technical object and its environment and it also depends on effectiveness of improvement actions. Return to the identification stage is performed after rational assessment of the object's operation. It is not a return to the starting point because the knowledge gained from the preceding identification stage, has been enriched with observations made during the preceding cycle.

Quantification of fire hazard level of a given ship area consists in determining fire progress depending on characteristics of particular elements of the area. It depends especially on 


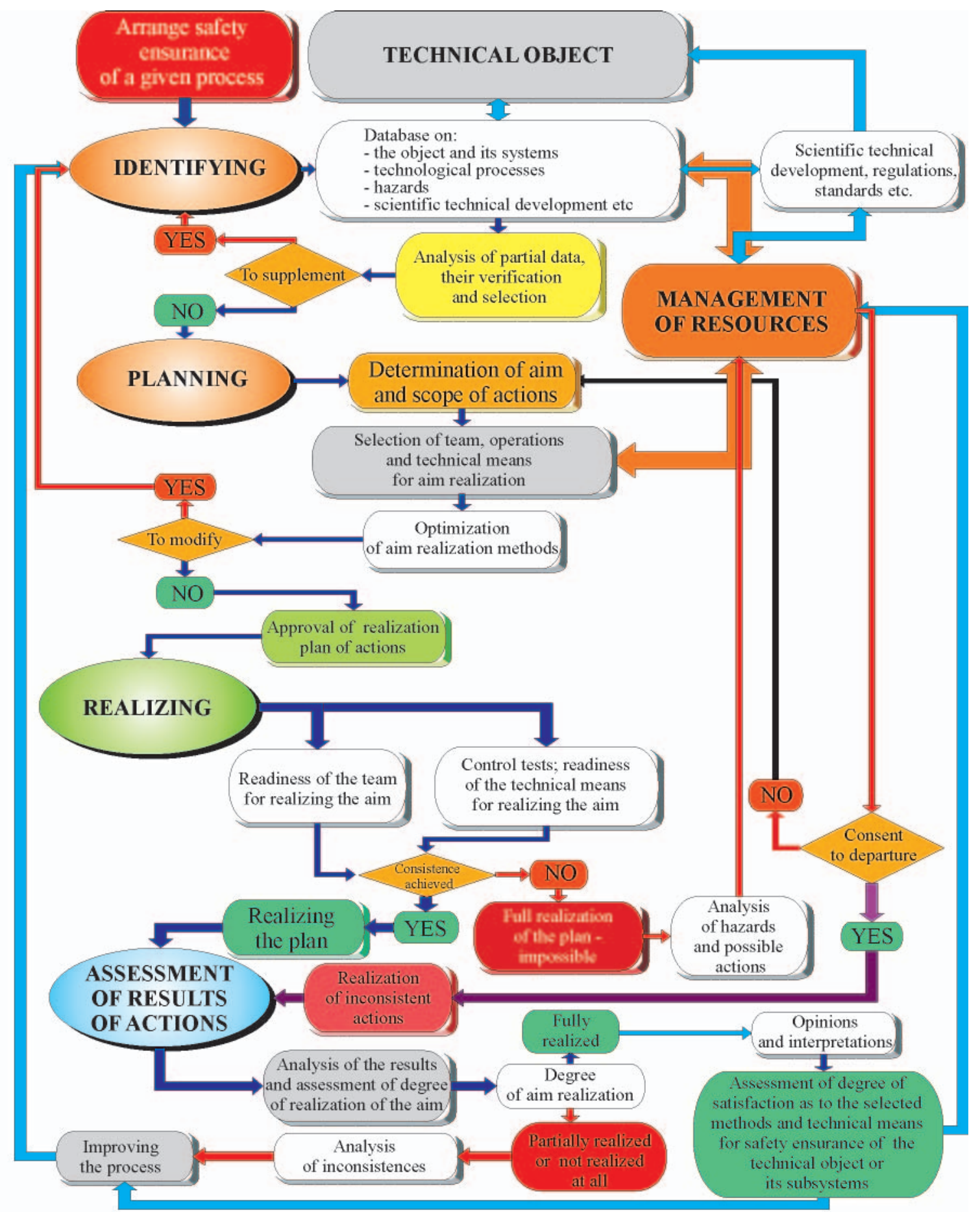

Fig. 4. Algorithm of the system of analysis and evaluation of effectiveness of applied safety measures

controllable features which constitute decisive parameters. Threshold analysis methods are useful to solve problems connected with safety of whole ship or its components. Barriers in safety systems may have control-informative function in the case of unwanted energy outflow, or protective function for technological process or state of technical object prior to occurrence of such outflow. If selection of an effective barrier cannot be made because of technological reasons or excessive costs, an administrative procedure should be elaborated for managing the level of defined and accepted hazard.

Fire progress control is possible in pre-ignition phase $[1,2]$ if the disposable heat abstraction intensity $\mathrm{q}_{\mathrm{sd}}$ of the endangered area (Fig. 5) is higher than the heat release rate of burning materials and thermal power of external ignition sources:

$$
\dot{\mathrm{q}}_{\mathrm{sd}}(\mathrm{t}) \geq \dot{\mathrm{q}}_{\mathrm{poz}}(\mathrm{t})=\dot{\mathrm{q}}(\mathrm{t})+\dot{\mathrm{q}}_{\mathrm{z}}(\mathrm{t})-\dot{\mathrm{q}}_{\mathrm{s}}(\mathrm{t})
$$

where:

$\dot{\mathrm{q}}_{\text {poż }}$ - fire power $[\mathrm{kW}]$

$\dot{q}^{-} \quad$ heat release rate of the process of thermal decomposition and burning the materials embraced by the fire [kW]

$\mathrm{t} \quad$ - time $[\mathrm{s}]$

$\dot{\mathrm{q}}_{\mathrm{z}} \quad$ - thermal power of external ignition sources $[\mathrm{kW}]$

$\dot{\mathrm{q}}_{\mathrm{s}} \quad-$ loss of heat per unit of time $[\mathrm{kW}]$.

The fighting with fully spread fire (i.e. rescue actions) is undertaken in a failure stage of an object or its components which is out of control. It indicates that the applied safety systems have not been capable of controlling the progress of the failure stage of the object.

There are many situations which favour fire ignition when a ship is under repair. These are such processes as: the repairing and changing of installations and ship devices, maintenance 


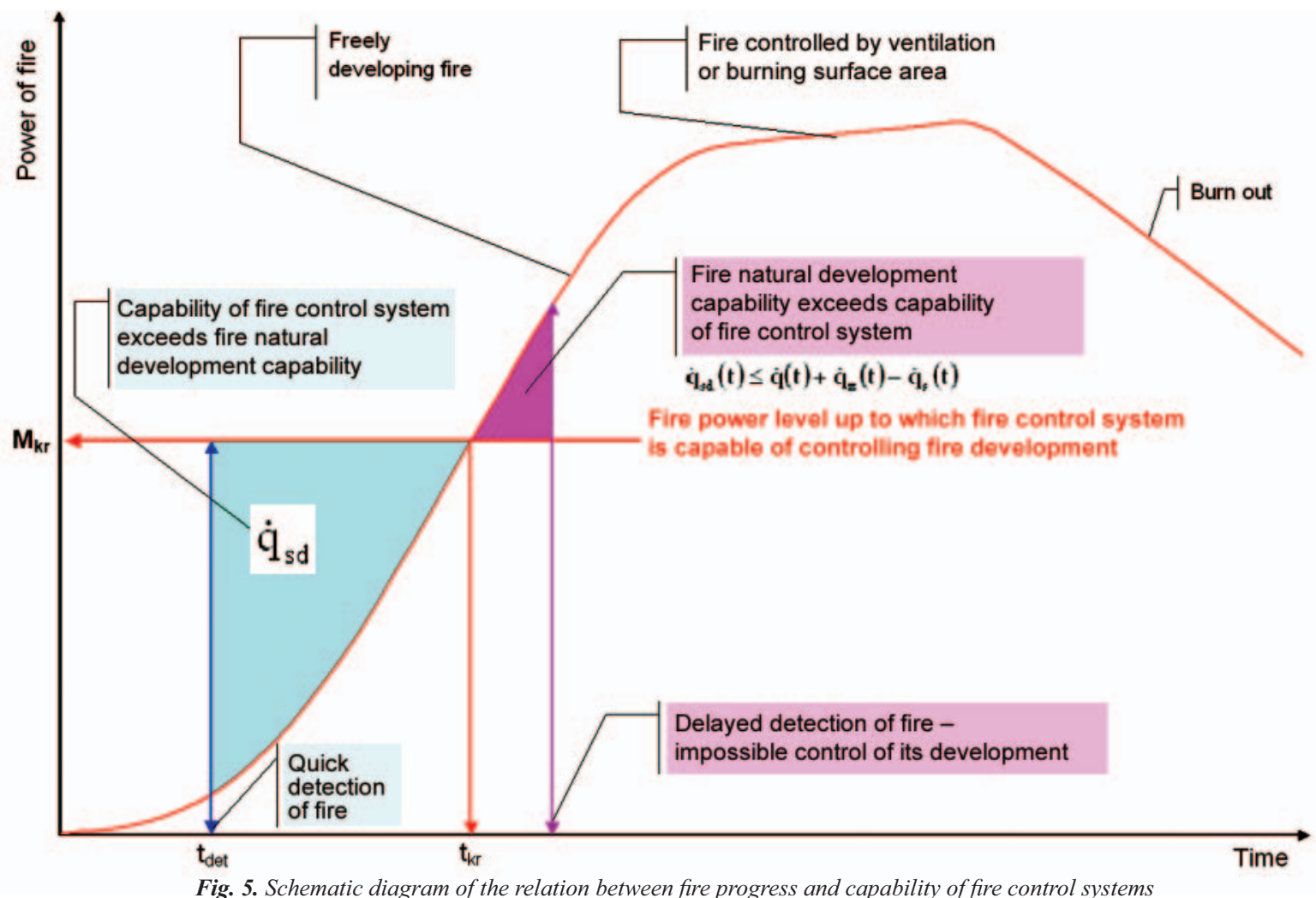

and other operations associated with a potential fire hazard, e.g. welding, metal element gas cutting, metalworking, painting and maintaining work etc. The dismantling of many installations carried out on a ship or its disable state resulting from its stay in shipyard or from performed survey may lead to fire hazard; for example, the abnormal functioning of ship devices may be a reason for some improvisations and provisional starting the substitute devices. During repair work certain necessary flammable materials, such as: paints, wood, insulation materials, stuffing, oils and solvents and other flammable agents for rinsing the mechanisms are usually brought into the ship. When ship is under repair many wastes, garbage, parts of dismantled devices, spilled liquids and dirt are produced. The littering generates fire hazard as it favours starting a fire.

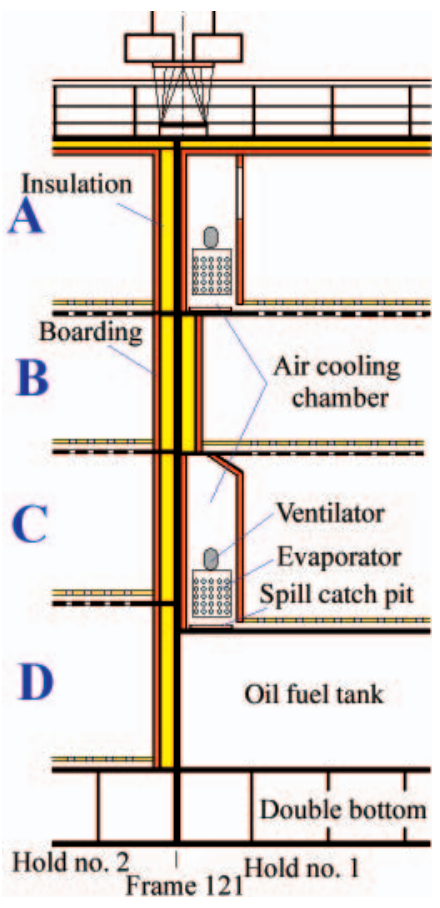

\section{EXAMPLE SELECTION OF ACTIONS AND MEASURES TO ENSURE SAFETY DURING REPAIR WORK}

An analysis of all possible fire hazards during ship repair is not included in this study. This part of the study is devoted to presentation of an example selection of actions and measures to ensure safety during repair work (welding) carried out in the bottom oil fuel tank located in the refrigerated hold no. 1 of a refrigerated vessel of old type, shown in Fig. 6.

It is necessary to identify all flows of unwanted energy or mass not only with regard to safety of people and technical object but also regarding operational costs of a given technological process or the whole technical object. Quantitative values of energy and mass flow rates, either known or potential, must be determined experimentally. Then on this basis their limit values must be defined, and devices intended for preventing the outflow and a system for minimizing the effects of unwanted energy outflow, have to be selected.

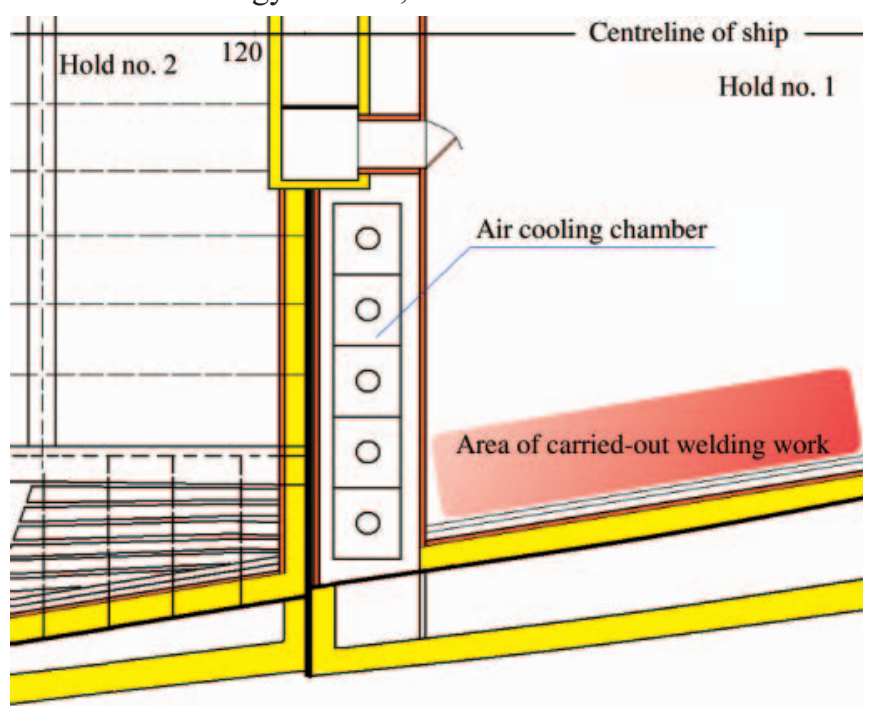

Fig. 6. Location of welding work carried out in oil fuel tank of the example refrigerated ship 
The welding work carried out on the bottom of the hold no. 1 generates serious fire hazard. The temperature of oxyacetylene torch flame exceeds $1500^{\circ} \mathrm{C}$. It is an essential possible cause of fire accident. Heating the burning metal, spread of metal particles dropping off the cutting gap, and dripping drops of fused metal are a potential source of ignition of flammable materials. Metal particles are also blown in direction of operating flame due to high pressure of gas at the torch outlet. All the things generate fire hazard for (Fig. 6.):

$\Rightarrow$ the starboard hold wall, made of flammable lacquered plywood

$\Rightarrow$ the polyurethane thermal insulation placed behind the hold wall

$\Rightarrow$ the air ventilation and cooling chamber.

The system in question is characterized by such advantages as completeness, objectivity and selectiveness [1,2]. On the basis of ship technical specification a graphical network of connections between causes and effects is created at all connection levels. For each possible pair of the network nodes
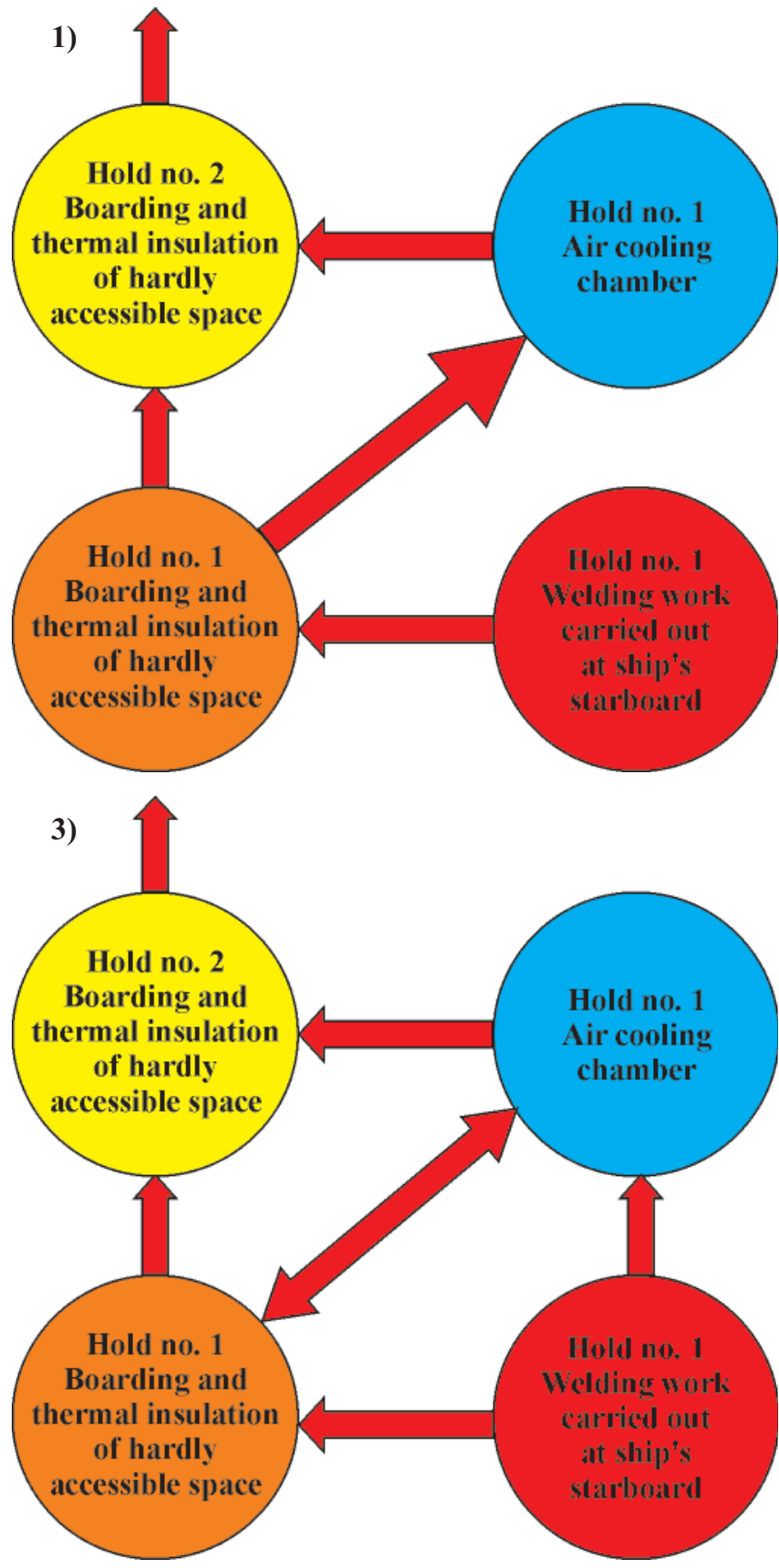

Fig. 7. Probable variants of fire progress
(Fig. 7) a hazard level analysis is conducted with regard to effectiveness of the applied measures for passive and active fire protection.

Fire hazard to the boarding and thermal insulation of the hold no. 1 and 2 is introduced by fire characteristics of lacquered waterresistant hard plywood, hard polyurethane foam and inflammable mineral wool of low value of permissible temperature for its application. It is also caused by specific construction of hardly accessible spaces (Fig. 1 and 8) resulting from the adjustment of refrigerated holds to shipping the palletised cargo.

The cross-section area of hardly accessible spaces varies between $0 \div 2 \mathrm{~m}^{2}$ depending on hull curvature of refrigerated vessel. Such spaces located between holds are separated by steel bulkheads. That is why the fire can be transferred from one hold to another by heat conduction. Moreover the air circulation is used to dry the thermal insulation in hardly accessible spaces in order to prevent a decrease of its insulation features. It means that the set of hardly accessible spaces connected with the air ventilation system of the holds favours fire progress on the ship (due to developed flue draft).
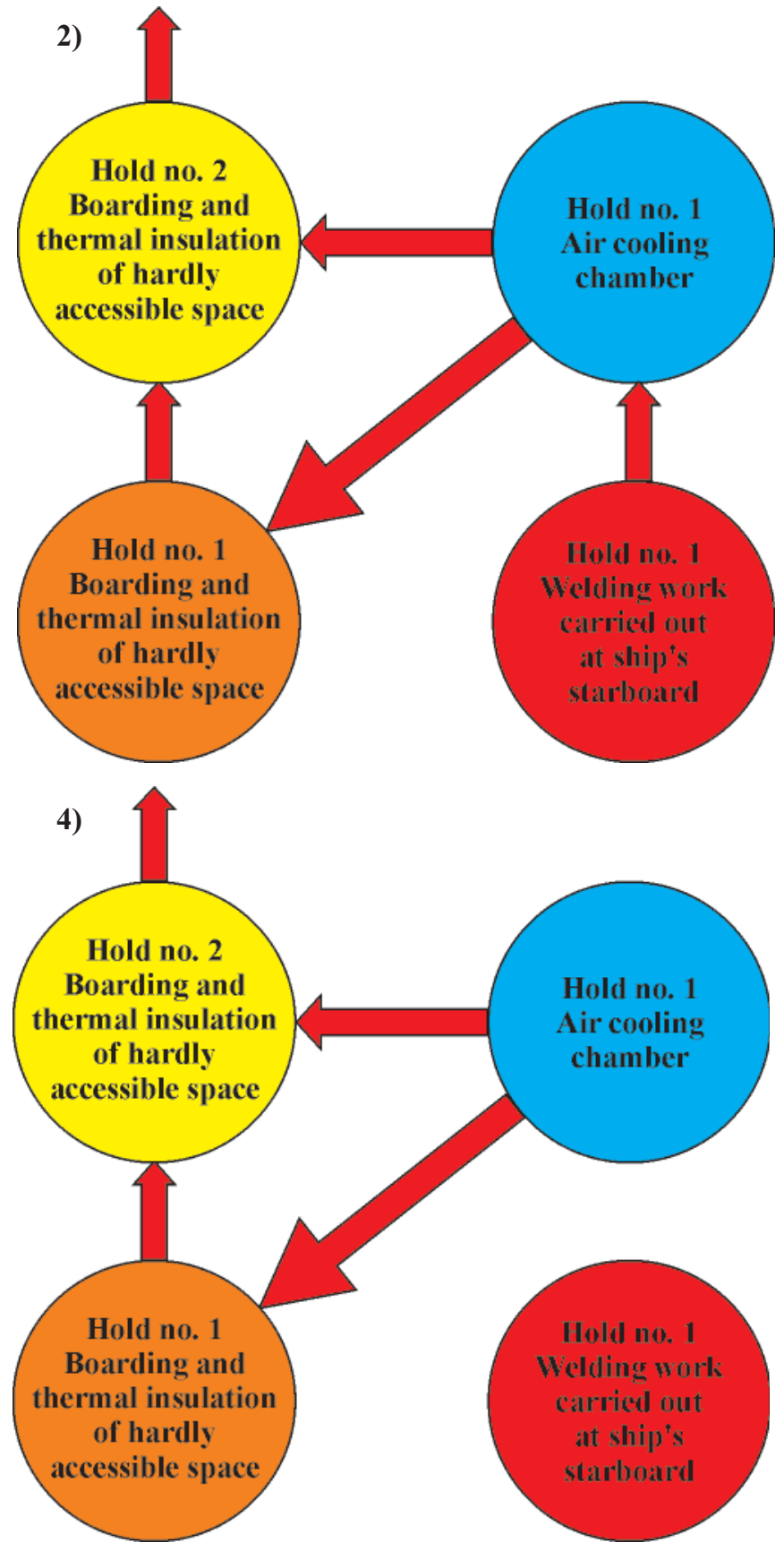


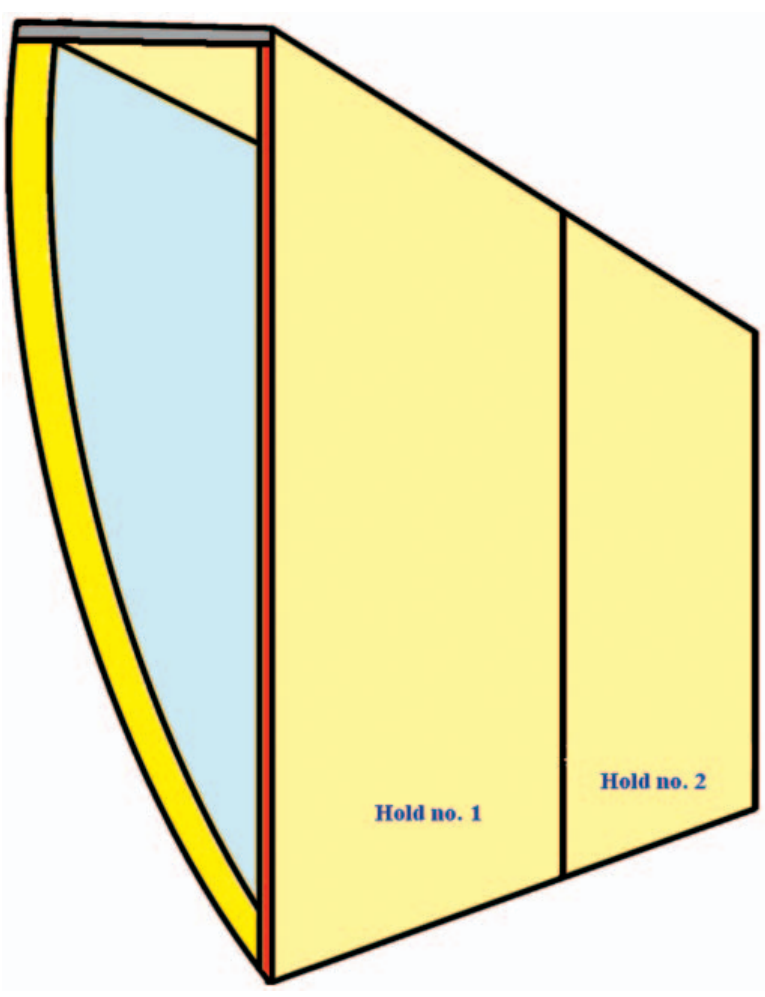

Fig. 8. Schematic cross-section of hardly accessible side spaces

\section{FIRE CHARACTERISTICS OF TYPICAL MATERIALS WHICH CAN CONTRIBUTE TO FIRE PROGRESS}

The determining of fire characteristics of typical materials which can contribute to fire progress in its initial, pre-ignition phase is an important element in predicting the fire progress.

Tests on fire characteristics of thermal insulation and boarding materials was carried out with the use of the methods complying with the International Code for Application of Fire Test Procedures (IMO FTP Code) [3] and ISO standards. Various materials applied to refrigerated vessel were tested. Out of all measured parameters and their derivatives, only the parameters which influence hard polyurethane foam behaviour in the initial phase of fire progress in the refrigerated hold, are presented in this study. They represent first of all influence of the conditions for thermal decomposition and combustion of hard polyurethane foam on heat release intensity, oxygen demand, smoke emission intensity and mass emission of oxygen and carbon dioxide.

The test results revealed that only the mineral wool can be deemed fully inflammable (Tab. 1)

Tab. 1. Test results of mineral wool fire characteristics according to the method given in Part 1 of IMO FTP Code [3]

\begin{tabular}{|c|c|c|}
\hline Duration of sustained flaming & $\mathbf{0 . 0 0}$ & $\mathbf{s}$ \\
\hline $\begin{array}{c}\text { Rise of furnace temperature above the final } \\
\text { furnace temperature }\end{array}$ & 6 & ${ }^{\circ} \mathrm{C}$ \\
\hline $\begin{array}{c}\text { Surface temperature above the final furnace } \\
\text { temperature }\end{array}$ & 5 & ${ }^{\circ} \mathrm{C}$ \\
\hline $\begin{array}{c}\text { Rise of temperature in the centre of the } \\
\text { specimen }\end{array}$ & 2 & ${ }^{\circ} \mathrm{C}$ \\
\hline Loss of weight of specimen & 7.98 & $\%$ \\
\hline
\end{tabular}

The disadvantage of mineral wool used for thermal insulation is its low limiting temperature for use as the mineral wool melts in the temperature of $750{ }^{\circ} \mathrm{C}$ creating glassy mass of a small volume. When shrinking it creates a free space behind the boarding, that favours development of flue drafts and gas exchange in the space (Fig. 9). This feature may contribute to fast fire progress in the space behind the shoring.

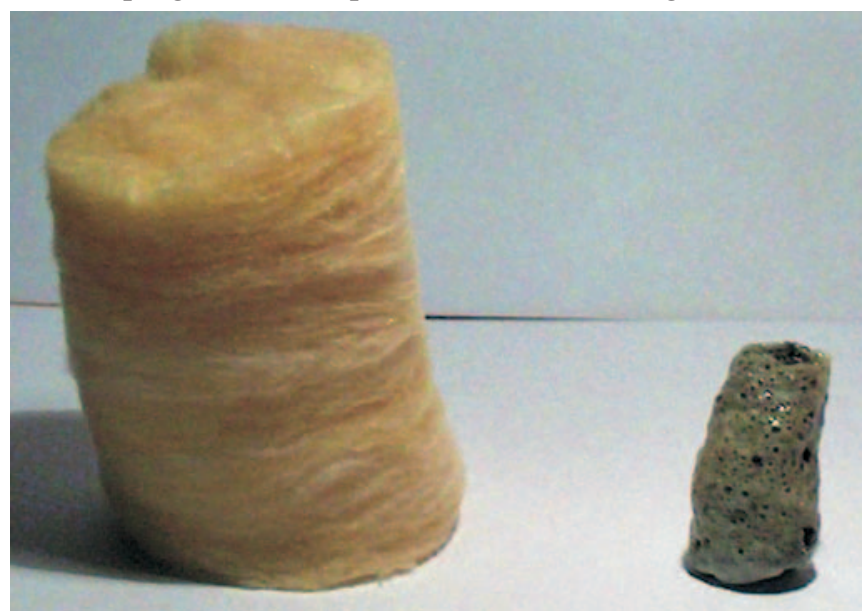

Fig. 9. The view of mineral wool sample before and after the fire tests

According to [3] the laminated plywood and hard polyurethane foam are flammable materials hence flames propagate fast on their surface (Tab. 2 and 3).

Tab. 2. Test results on surface flammability rate of lacquered water-resistant plywood of $20 \mathrm{~mm}$ in thickness, according to the method given in Part 5 of IMO FTP Code [3]

\begin{tabular}{|c|c|c|}
\hline Critical flux at extinguishment & 12.74 & $\mathrm{~kW} / \mathrm{m}^{2}$ \\
\hline Heat for sustained burning & 1.50 & $\mathrm{MJ} / \mathrm{m}^{2}$ \\
\hline Peak heat release rate & 4.20 & $\mathrm{~kW}$ \\
\hline Total heat release & 4.88 & $\mathrm{MJ}$ \\
\hline Fall of heavy drops & \multicolumn{2}{|c|}{ it does not occur } \\
\hline
\end{tabular}

Tab. 3. Test results on surface flammability rate of hard polyurethane foam according to the method given in Part 5 of IMO FTP Code [3]

\begin{tabular}{|c|c|c|}
\hline Critical flux at extinguishment & 3.65 & $\mathrm{~kW} / \mathrm{m}^{2}$ \\
\hline Heat for sustained burning & 0.20 & $\mathrm{MJ} / \mathrm{m}^{2}$ \\
\hline Peak heat release rate & 5.44 & $\mathrm{~kW}$ \\
\hline Total heat release & 1.08 & $\mathrm{MJ}$ \\
\hline Fall of heavy drops & \multicolumn{2}{|c|}{ it does not occur } \\
\hline
\end{tabular}

Besides, the tests showed that boarding made of lacquered water-resistant plywood, due to its thermal potential and the average constant heat release intensity of $50 \mathrm{~kW} / \mathrm{m}^{2}$, will intensify fire progress from thermal insulation.

The value of heat of combustion of the hard polyurethane foam, determined according to the method of ISO 1716, amounts to $26.80 \mathrm{MJ} / \mathrm{kg}$.

The hard polyurethane foam is an intensively smoke emitting material (Tab. 4) according to the requirements of Part 2, IMO FTP Code [3]. During thermal decomposition of the polyurethane foam an intensive smoke emission appears first, then its flame combustion occurs (Fig. 10). It means that the flameless intensive smoke emission is a symptom of fire.

Tab. 4. Test results on smoke-producing rate of hard polyurethane foam, according to the method given in Vol. 2 of IMO FTP Code [3]

\begin{tabular}{|c|c|c|}
\hline Time of sample ignition & 1.10 & $\mathrm{~S}$ \\
\hline Maximum optical specific density & 590.70 & - \\
\hline $\begin{array}{c}\text { Maximum speed of changes of optical } \\
\text { specific density }\end{array}$ & 21.99 & $1 / \mathrm{s}$ \\
\hline
\end{tabular}




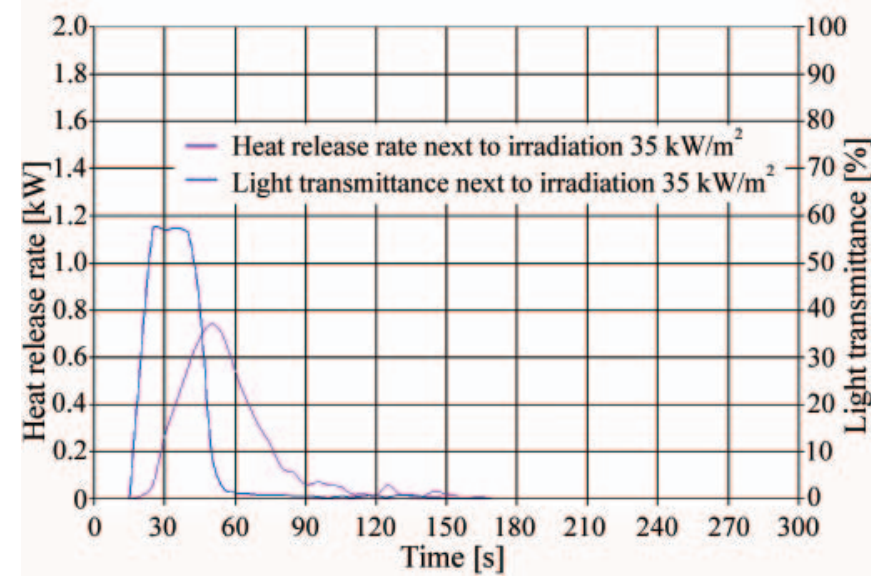

Fig. 10. Relationship between heat release intensity during thermal decomposition and combustion of hard polyurethane foam and transmittance of light passing through the layer of combustion products and time, recorded during the tests carried out according to the ISO 5660-1 method, at $35 \mathrm{~kW} / \mathrm{m}^{2}$ heat flux intensity on sample surface

Sparks formed during welding belong to the group of lowpower ignition sources. For this reason, tests on ignitability were performed according to the method of PN-EN ISO 11925-2. Hard polyurethane foam lit in vertical position first ignites and then the burning dies down spontaneously after several tens of seconds. Besides, hard polyurethane foam is not characterized by progressive incandescence. It means that the foam applied to the insulation system of refrigerated hold, if ignited by welding spark or gas torch flame, will not transfer fire behind the boarding. It does not show the drop fall-off which is typical for plastics. Tests on surface flammability rate prove occurrence of this feature (Tab. 3). The value of the heat flux critical for the tested foam amounts to $3.65 \mathrm{~kW} / \mathrm{m}^{2}$. The critical heat flux is a measure of ignition source thermal power necessary for starting self-sustaining process of combustion of the material. Such behaviour results from a specific chemical structure of this group of plastics. Polyurethanes are polymers which are formed in the process of poly-addition of polyfunctional organic isocyanates (two- and higher functional) with two- or higher functional compounds containing hydroxyl groups connected with aliphatic carbon atoms (glycols and polyols). Polyesters (prepared from adipic acid and ethylene, methylene, propylene glycol and also polyhydric alcohols) or poly-ethers (there are usually additive connections of propylene oxide with polyhydric alcohols); also, ricinus oil and its derivatives are often used. Hydrogen chloride content in products of thermal decomposition and combustion (Tab. 5) points to halohydrocarbon frothing agent.

On the basis of the presented test results of fire characteristics of the following system of materials: metal plate, hard polyurethane foam, laminated plywood, it was stated that the fire is unlikely to be transferred behind the boarding. However, occurrence of combustion of the boarding due to external flame is always possible.

Fire hazard to the ventilation air cooling block is mainly produced by:

the flammable boarding made of lacquered water-resistant hard plywood, used for the partitions of the air cooling chamber

$>$ the fact that the chamber is a hardly accessible space

$>$ the flammable tarry and dusty contamination of the chamber's internal surfaces, which always occurs during operation of the ventilation systems; in air cooling systems such contaminations settle in lower part of the compartment

$>$ the oil contamination of the air cooling chamber's internal surfaces (Fig. 11 and 12), which may be formed when an unsealing of the cooling installation occurs (up to $10 \%$ of oil is contained in circulating refrigerant); a water content in oil accelerates oil deterioration and other negative effects including acid formation, which leads to corrosion of metals

$>$ short-circuit in the electrical system may create an ignition source for flammable materials.

Summing up, probability of fire accident in the analyzed air cooling chamber is very high. Fire ignition sources may be produced by the heat metal particles created during cutting, blown into a cooling ventilation blowing gap in the direction of gas torch flame as a result of high gas pressure at its outlet, or a short-circuit in the electrical system. The fire initiated in the cooling chamber may progress invisibly for a long time because, when the hold ventilation is switched off during ship repair, the air will enter the air cooling chamber through a blowing gap at the floor, and fire products will propagate along ventilation ducts of the system, including air freshening ones installed in the hold. Smoke produced during cutting with the use of oxyacetylene torch will favour this process. Such fire will be revealed in its ignition phase or when the next of hardly accessible spaces will be under fire. Fire will appear always in a certain distance from its source. It may cause extinguishing

Tab. 5. Test results on mass emission of toxic products of thermal decomposition and combustion of hard polyurethane foam according to the method of PN-B-02855 standard

\begin{tabular}{|c|c|c|c|c|c|c|c|}
\hline \multirow{2}{*}{$\begin{array}{c}\text { Decomposition } \\
\text { temperature }\end{array}$} & & \multicolumn{6}{|c|}{ Specific emission of toxic products } \\
\hline & & $\mathbf{C O}$ & $\mathbf{C O}_{\mathbf{2}}$ & $\mathbf{H C N}$ & $\mathbf{N O}_{\mathbf{2}}$ & $\mathbf{H C l}$ & $\mathbf{S O}_{\mathbf{2}}$ \\
\hline & & {$[\mathrm{mg} / \mathrm{g}]$} & {$[\mathrm{mg} / \mathrm{g}]$} & {$[\mathrm{mg} / \mathrm{g}]$} & {$[\mathrm{mg} / \mathrm{g}]$} & {$[\mathrm{mg} / \mathrm{g}]$} & {$[\mathrm{mg} / \mathrm{g}]$} \\
\hline \multirow{4}{*}{$\mathbf{4 5 0}^{\circ} \mathbf{C}$} & Specimen no 1 & 14.06 & 41.74 & 0.23 & 0.01 & 1.09 & 0.00 \\
\cline { 2 - 8 } & Specimen no 2 & 22.92 & 54.84 & 0.31 & 0.01 & 2.04 & 0.00 \\
\cline { 2 - 8 } & Specimen no 3 & 22.92 & 54.84 & 0.27 & 0.01 & 1.55 & 0.00 \\
\cline { 2 - 8 } & Average & 18.49 & 48.29 & 0.27 & 0.01 & 1.56 & 0.00 \\
\hline \multirow{4}{*}{$\mathbf{5 5 0}^{\circ} \mathbf{C}$} & Specimen no 1 & 153.39 & 284.41 & 6.06 & 0.01 & 29.73 & 0.00 \\
\cline { 2 - 8 } & Specimen no 2 & 169.53 & 326.97 & 6.11 & 0.01 & 31.09 & 0.00 \\
\cline { 2 - 8 } & Specimen no 3 & 169.53 & 326.97 & 6.03 & 0.01 & 30.25 & 0.00 \\
\cline { 2 - 8 } & Average & 161.46 & 305.69 & 6.08 & 0.01 & 30.41 & 0.00 \\
\hline \multirow{4}{*}{$\mathbf{7 5 0}^{\circ} \mathbf{C}$} & Specimen no 1 & 41.41 & 1097.95 & 1.71 & 0.03 & 4.17 & 0.00 \\
\cline { 2 - 7 } & Specimen no 2 & 83.59 & 1057.85 & 1.43 & 0.02 & 9.54 & 0.00 \\
\cline { 2 - 7 } & Specimen no 3 & 83.59 & 1057.85 & 1.60 & 0.02 & 6.54 & 0.00 \\
\cline { 2 - 7 } & Average & 62.50 & 1077.90 & 1.57 & 0.02 & 6.86 & 0.00 \\
\hline
\end{tabular}


measures to be directed to an area where only fire products are revealed.

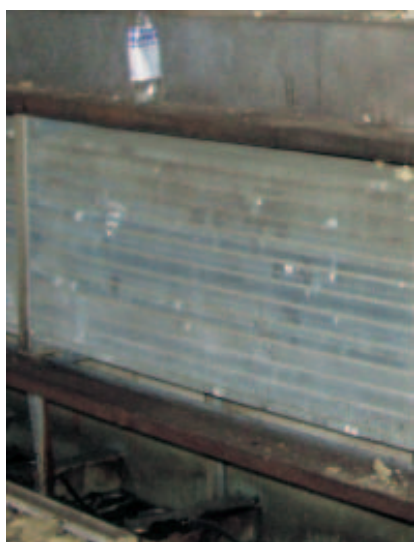

Fig. 11. Oil contamination visible on the walls of cooling chamber

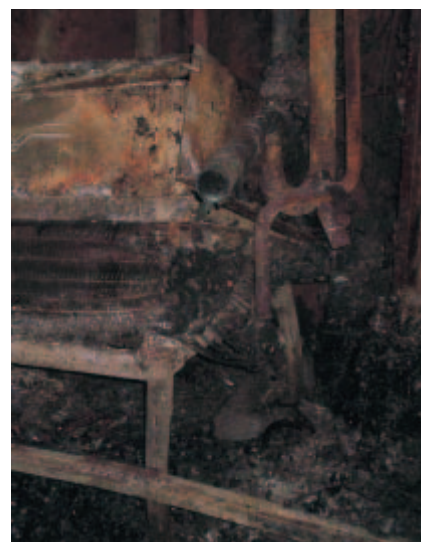

Fig. 12. Open ducts of air cooling system (the view after fire accident)
During this time the heated metal bulkhead which divides the holds, will transfer the fire to the next hold as a result of heat conduction.

The presented hazard identification with regard to the specificity of the construction and equipment of the hold of the refrigerated vessel of old type, during the repair carried out in oil fuel tank in the hold no. 1, indicates that selection of fire safety actions and technical measures should be so performed as to prevent fire to ignite in hardly accessible spaces behind the boarding of hold walls and in air cooling chambers because, due to flue drafts, the fire may very fast propagate to the next holds and compartments of the ship.

Fire in air cooling chambers is very dangerous due to its possible dynamics. Contamination and oiling-up internal surfaces of the boarding of such spaces accelerate fire propagation over the surfaces, increasing this way its power.

\section{THE APPLIED FIRE SAFETY MEASURES AND FINAL REMARKS}

The measures selected to reach the optimum solution of the example fire safety problems associated with the repairing of oil fuel tank in the refrigerated hold no. 1 of the ship in question, are as follows :

* the detailed knowledge of the ship's technical documentation with special regard to specificity of construction and equipment of the area where maintenance and repair work are planned to be carried out

* the opening of the hardly accessible spaces by removing all the boarding of the hold walls in the area of the planned welding work

* the cleansing of the exposed internal surfaces of the air cooling chamber off the contaminations

* the making of inspection holes to monitor adjacent hardly accessible spaces over all the height of the hold because the ship's technical documentation may not include all existing air flow ducts

* the hazard level evaluation

* the selecting of a team, operating actions and technical measures, to perform the task

* the continuous monitoring of neighbouring hardly accessible spaces during repair work, on all height levels of the hold under repair and the neighbouring holds

* the usage of local extinguishing equipment to extinguish possible local ignitions of residues of flammable materials in the repair work area and hardly accessible spaces.
Internal fire extinguishing requires special techniques. Extinguishing activities must slow down the process of thermal decomposition and combustion of flammable materials by limiting oxygen inflow and by heat abstraction. Insulation features of the boarding made of lacquered water-resistant (nonabsorbable) plywood make the internal fire extinguishing low efficient when using water stream directed to the external surface of this boarding. The extinguishing agent must be put inside these spaces. It requires to prepare an appropriate number of holes to make control of hardly accessible spaces possible before beginning the repair work and in case of fire; extinguishing measures such as, for example, a fire- extinguishing foam which limits fire propagation, must be used

Slowing down the fire progress in pre-ignition phase results from the applied barriers hence their properties should be so selected as to comply with object's operational conditions. The barriers are: passive or active screens, extinguishing systems, fire-resistant features of materials and construction, systems for control of dynamics of fire progress and propagation of its products, procedural and administrative requirements, etc.

A traditional approach to fire safety, which consists in removing the boarding and thermal insulation only from the area of immediate spread range of welding sparks, has turned out to be inefficient fire protection of repair work, in practice. The presented example fire accident on the refrigerated vessel during repair covered three holds out of four, causing significant financial losses.

The quantitative evaluation of fire hazard level is the basic measure of the policy of ship fire safety. This measure, instead of "curing" the fire damage effects, is focused on the complex approach to ship fire safety and on the preventing of possible negative effects of fire hazards. Therefore, to properly select such measures the possibly comprehensive description of ship environment, its complexity and the prediction of its changes resulting from fire hazard effects, is necessary.

Basic tasks of fire safety engineering of technical objects include:

$i$ prediction of possible fire hazards and limiting them at the planning stage of object operation

is selection of appropriate fire safety systems and technical devices, and their technical and operational parameters, as well as the principles for operational procedures which ensure safety for operators of such objects and their systems, and minimize possible hazard to the environment.

\section{BIBLIOGRAPHY}

1. Sychta Z:: The slowing down of the process of thermal decomposition and combustion of materials - the basic condition for fire safety of technical objects (in Polish). Szczecin University of Technology, Prace naukowe (Scientific reports), No.570, 2002

2. Quantification problems of fire-safety level of marine object. Polish Academy of Sciences, Branch in Gdańsk Marine Technology Transactions. Vol.16, 2005

3. International Code for Application of Fire Test Procedures. International Maritime Organization. London 1998

\section{CONTACT WITH THE AUTHORS}

Zygmunt Sychta, Prof. Faculty of Marine Technology, Szczecin University of Technology

Al. Piastów 41

71-065 Szczecin, POLAND

e-mail : zygmunt.sychta@ps.pl 